ORIGINAL ARTICLE

\title{
Frequency of Depression, Anxiety and Stress among Gynae Residents during Covid Pandemic
}

\author{
IMRAN KHAN ${ }^{1}$, MUHAMMAD ZAMAN AFRIDI ${ }^{2}$, ZAHRA WASIM ${ }^{3}$, NADIA KHAN JAWAD ${ }^{4}$, ZUBAIDA KHANUM WAZIR ${ }^{5}$, \\ SHAKIL ASIF \\ ${ }^{1}$ Assistant Professor Psychiatry Unit, Khyber Teaching Hospital, Peshawar \\ ${ }^{2}$ Psychiatry Registrar, Life Promotion Clinic Griffith University \\ ${ }^{3}$ Classified Gynaecologist CMH, Risalpur \\ ${ }^{4}$ Assistant Professor Gynae and Obs, Jinnah International hospital, Women Medical College, Abbottabad \\ ${ }^{5}$ Assistant Professor Gynae/Obstetrics, Bannu Medical College, Bannu \\ ${ }^{6}$ Associate Professor Psychiatry, Mohtarma Benazir Bhutto Shaheed Medical College/ Div HQ hospital, Mirpur AJK \\ Corresponding author: Dr. Muhammad Zaman Afridi, Email: m.afridi@griffith.edu.au, Cell: +61 469062733
}

\begin{abstract}
Objective: To find the frequency of depression, anxiety and stress among Gynae residents during covid pandemic.

Methodology: This Cross-sectional survey was carried out in different Teaching Hospitals of Khyber Pakhtunkhwa during the period of six months i.e from August 2020 to January 2021. After the ethical approval from the research committee, data was collected from Post Graduate Gynae Residents of Teaching Hospitals. Sample size for the study was 405 participants. Depression, anxiety and gross scale shorten version DASS-21 containing 21 items was standard research to use in study i.e. depression, anxiety and stress was identified on the basis of their cutoff scores i.e. normal scores were $\geq 10, \geq 8$ and $\geq 15$ for depression, anxiety and stress respectively.

Result: In depression, 136 (34\%) participants were normal followed by moderate level having frequency 121 $(30.25 \%)$. In the anxiety category, $116(29 \%)$ participants were normal followed by moderate level having frequency 101 (25.5). In the category of stress, 179 (44.75\%) participants were normal followed by mild levels having frequency $106(26.50 \%)$. Only COVID positive status was statistically significant with depression, anxiety and stress as their P-valve was 0.02 less than 0.05 .

Conclusion: Considerable number of post graduate Gynae trainees working in different tertiary care hospitals have varying degrees of depression, anxiety and stress due to COVID-19 pandemic.

Keywords: COVID-19, Pandemic, Post graduate, Psychological impact, Trainee doctors, Gynae residents, Mental health, Obstetrics, Gynaecology.
\end{abstract}

\section{INTRODUCTION}

Corona virus disease 2019 or COVID-19 is caused by recently identified Corona Virus (1,2). On 12 march 2020, the World Health Organization declared the COVID outbreak as a worldwide pandemic (3).

Various psychological problems and serious threats were triggered and caused by COVID-19 pandemic. Medical doctors and healthcare professionals working in different COVID wards experienced certain psychological symptoms like depression was reported by $50.4 \%$ healthcare workers while anxiety, insomnia and distress were reported by $44.6 \%, 34 \%$ and $71.5 \%$ healthcare workers respectively (4).

COVID pandemic increased difficulties for healthcare workers like SARS-CoV and Middle East respiratory syndromes pandemics in the past. Increased workload during duty hours, limited supply of protective equipment like PPEs, masks etc. and fear of getting infections along with frustration and non-availability of life saving resources are certain factors maximizing psychological problems (5).

According to the results of recently done research on Healthcare workers (HCWs) are more susceptible to pandemic due to which it increases psychological distress among them (6-8). There is scarcity of evidence regarding prevalence of depression in low and middle income countries, but recently a study was done in India regarding depression in $\mathrm{HCWs}$, and they reported $32.6 \% \mathrm{HCWs}$ with depression, which was much higher if compared with general population reporting only $10 \%$ prevalence of common menial disorders (9).

Post graduate trainee doctors during their training period mutually reported high prevalence of psychological problems like anxiety and depression. Research studies reveal $14 \%$ of early exhaustion while $12.4 \%$ resident doctors reported advanced exhaustion (10, 11). Different psychological problems like anxiety, depression, restlessness or insomnia and denial maximum due to future uncertainty of result of COVID pandemic. On post graduate trainee resident, a study was conducted reporting high prevalence i.e. $26.4 \%, 22.6 \%$ and $4.4 \%$ of depressive symptoms, generalized anxiety disorder and acute stress disorder (12). The most vulnerable and exposed unit reporting high incidence of COVID are Otolaryngology $21 \%$ of residents of Otolaryngology reported exhaustion and burn out in different hospitals of the United states of America (13).

The purpose of this study is to determine the psychological impact of depression, anxiety, and stress among postgraduate gynaecology residents working in various tertiary care hospitals in Pakistan, as well as the relationship between their marital status, year of training, and whether they or a family member has been infected with COVID disease. This research would focus on the most vulnerable members of the medical community. 
Imran Khan, Muhammad Zaman Afridi, Zahra Wasim et al

\section{METHODOLOGY}

This Cross-sectional survey was carried out in different Teaching Hospitals of Khyber Pakhtunkhwa during the period of six months i.e from August 2020 to January 2021. After the ethical approval from the research committee, data was collected from Post Graduate Gynae Residents of Teaching Hospitals. Sample size for the study was 405 calculated through open EPI sample size calculator with confidence interval of $95 \%$ and margin of no response $5 \%$. Convenience sampling technique was used in study. Post graduate Gynae residents were included in the study while those who were on psychological treatment before COVID were excluded. Depression, anxiety and stress scale shorten version DASS-21 containing 21 items was standard research to use in study i.e. depression, anxiety and stress was identified on the basis of their cutoff scores i.e. normal scores were $\geq 10, \geq 8$ and $\geq 15$ for depression, anxiety and stress respectively. Each item of the DASS-21 questionnaire is categorized into four categories i.e. 0 for never, 1 for sometimes, 2 for often and 3 for always. Statistical analysis of the elected data was done on SPSS version 20. Association between variables was found through chi-square test. $P$ value of $\leq 0.05$ was considered statistically significant. Result was shown in table and groups.

\section{RESULT}

Calculated sample size of our study was 405 and Response rate of our study was $98.76 \%$ thus 400 Gynae residents gave response to our questionnaire distributed in different hospitals. In demographics of results, mean age of the participants were $31.10 \pm 2.62$ years. In gender comparison, female was more i.e. $394(98.5 \%)$ while only 6 participants were males as Gynae is priority of females in our culture. On the basis of marital status, maximum residents were married having frequency 220 (56.5\%) followed by unmarried residents having frequency $170(41 \%)$ while 4 residents $(1 \%)$ were divorced. On the basis of years of experience, maximum residents were in their fourth year of training i.e. $149(37.25 \%)$ followed by $2^{\text {nd }}$ year of training having frequency $112(28 \%)$. Demographics of the study is shown in table $\mathrm{I}$.
Table 01: Demographics

\begin{tabular}{|l|l|l|l|}
\hline Variables & Categories & $\begin{array}{l}\text { Frequency } \\
(\mathrm{N})\end{array}$ & $\begin{array}{l}\text { Percentage } \\
\%\end{array}$ \\
\hline Gender & Female & 394 & $98.5 \%$ \\
\hline & Male & 06 & $1.5 \%$ \\
\hline Marital status & Unmarried & 170 & $42.5 \%$ \\
\hline & Married & 226 & $56.5 \%$ \\
\hline & Divorce & 04 & $01 \%$ \\
\hline Years of training & $1^{\text {st }}$ year & 75 & $18.75 \%$ \\
\hline & $2^{\text {nd }}$ year & 112 & $28 \%$ \\
\hline & $3^{\text {rd }}$ year & 64 & $16 \%$ \\
\hline & $4^{\text {th }}$ year & 149 & $37.25 \%$ \\
\hline COVID infection & Yes & 202 & $50.50 \%$ \\
\hline & No & 198 & $49.50 \%$ \\
\hline & & &
\end{tabular}

Table II of the study shows the frequency of depression, anxiety and stress among Gynae residents, along with their levels of normal, mild, moderate, severe and very severe. In depression, 136 (34\%) participants were normal followed by moderate level having frequency $121(30.25 \%)$. In anxiety category, $116(29 \%)$ participants were normal followed by moderate level having frequency 101 (25.5). in category of stress, 179 (44.75\%) participants were normal followed by mild levels having frequency 106 $(26.50 \%)$.

Table II: Frequency of depression, anxiety and stress among post graduate Gynae-residents

\begin{tabular}{|l|l|l|l|}
\hline & Depression N (\%) & Anxiety N (\%) & Stress N (\%) \\
\hline Normal & $136(34.0 \%)$ & $116(29.0 \%)$ & $179(44.75 \%)$ \\
\hline Mild & $95(23.75 \%)$ & $48(12.0 \%)$ & $106(26.50 \%)$ \\
\hline Moderate & $121(30.25 \%)$ & $101(25.25 \%)$ & $102(25.50 \%)$ \\
\hline Severe & $35(8.75 \%)$ & $82(20.5 \%)$ & $12(3.0 \%)$ \\
\hline Very severe & $13(3.25 \%)$ & $53(13.25 \%)$ & $1(0.25 \%)$ \\
\hline
\end{tabular}

Table III of the result shows association of depression, anxiety and stress with different variables of demographics like gender, marital status, years of training and COVID positive status. Chi square test was used to find association and COVID positive status was statistically significant with depression, anxiety and stress as their Pvalve was 0.02 less than 0.05 .

Table III: Association of Depression, Anxiety and Stress with study variables

\begin{tabular}{|l|l|l|l|l|l|l|l|l|}
\hline Variables & Categories & $\mathrm{N}(\%)$ & Depression & $\mathrm{p}$-value & Anxiety & $\mathrm{p}$-value & Stress & $\mathrm{p}$-value \\
\hline Gender & Female & $394(98.5 \%)$ & 14.5 & 0.13 & 13.7 & 0.23 & 15.7 & 0.43 \\
\hline & Male & $06(1.5 \%)$ & 12.2 & & 14.2 & & 16.4 & \\
\hline Marital status & Unmarried & $170(42.5 \%)$ & 12.3 & 0.98 & 10.8 & 0.14 & 14.6 & 0.62 \\
\hline & Married & $226(56.5 \%)$ & 12.3 & & 12.0 & & 14.6 & \\
\hline & Divorce & $04(01.0 \%)$ & 11.8 & & 17.1 & & 18.1 & \\
\hline Year of training & $1^{\text {st }}$ year & $75(18.75 \%)$ & 12.1 & 0.80 & 11.6 & 0.72 & 14.8 & 0.48 \\
\hline & $2^{\text {nd }}$ year & $112(28.0 \%)$ & 12.9 & & 11.0 & & 14.5 & \\
\hline & $3^{\text {dr }}$ year & $64(16.0 \%)$ & 12.4 & & 11.1 & & 14.9 & \\
\hline & $4^{\text {th }}$ year & $149(37.25 \%)$ & 11.9 & & 12.1 & & 14.1 & \\
\hline COVID infection & Yes & $202(50.50 \%)$ & 12.7 & 0.18 & 11.6 & 0.34 & 14.7 & 0.02 \\
\hline & No & $198(49.50 \%)$ & 11.9 & & 11.5 & & 14.9 & \\
\hline
\end{tabular}

\section{DISCUSSION}

As country is facing covid pandemic, not only affecting general community population but also healthcare workers both physically and mentally. Not only senior but also young and junior doctors had lost their lives in this covid situation for better future.

The result of our study showed high mean DASS score of depression followed by stress and then anxiety which are $8.17+3.30,5.34+3.12$ and $3.80+3.40$ respectively. In Pakistan, two studies were conducted, one 
in Karachi and another one in Lahore through web-media to assess mental health of healthcare workers performing their duties directly exposed to Covid patients. According to the results of the study done in Karachi, mean score of depression, anxiety and stress was $18.2,19.01$ and 20.12 respectively while results of study in Lahore showed 6.17, 5.80 and 7.34 DASS score for depression, anxiety and stress respectively $(14,15)$. Another study done in China on mental health status of frontline healthcare workers using DASS score showed lower frequencies of depression, anxiety and stress as compared to our study (16).

In this study DASS-21 was used to find the frequencies of depression, anxiety and stress and results showed 177(66.8\%) HCQs with depression, 198 (71.6\%) with anxiety and $150(56 \%)$ with stress respectively. In comparison of our study results with two studies done in Pakistan on doctors, the results of the study done by Sandesh et al in Karachi reported higher frequencies of depression, anxiety and depression while study done in Lahore showed lower frequencies $(14,15)$. Similar kind of study was conducted in Turkey showed higher frequencies of stress, anxiety and depression among general physicians i.e. $64.7 \%, 51.6 \%$ and $41.2 \%$ respectively (17). While study done by Lai $\mathrm{J}$ et. al on healthcare workers in China revealed higher frequencies of depression and anxiety related symptoms i.e. $50.4 \%$ and $44.6 \%$ respectively $(17,18)$.

According to the results of our study DASS symptoms didn't showed any significant association with independent variables of the study like age, gender, marital status and years of training but showed significant association with Gynae residents whose family members got infection. A study was conducted on trainee medical officers and results showed higher stress level in female trainee officers while higher level of depression and anxiety in unmarried trainee medical officers (19).

A comparative study was done by Kannampllil TG between physicians working in covid units and physicians not exposed to covid patients. Result of the study showed higher frequencies of stress, depression and anxiety among exposed physicians as compared to unexposed. Level of stress was $29.4 \%$ in exposed as compared to $18.9 \%$ in unexposed, depression was $46.3 \%$ in exposed as compared to $33.7 \%$ in unexposed while $21.6 \%$ anxiety were in exposed as compared to $14.9 \%$ in unexposed (19). Study done in Pakistan showed high burnout frequency in anesthesia and critical care units followed by Gynae and obstetrics unit (20).

The COVID-19 pandemic has a high psychological morbidity on health-care personnel all around the world, according to the literature. Stressors lurking beneath the surface must be addressed. Stress coping strategies and seminars must be organized in such a way that they are easily accessible (21). We must encourage them to embrace and employ various stress-reduction measures, as most health-care personnel were aware of the availability of institutional wellness programs and COVID emergency resources, but only $4-5 \%$ took advantage of them (21). As a result, providing a supportive working environment and increasing incentive to engage in healthy, stress-relieving activities is critical for maximum productivity during this pandemic. Furthermore, establishing large-scale mental health support programs for healthcare workers is critical $(22,23)$. Practical implementations of treatments must be ensured for improved outcomes (24).

\section{CONCLUSION}

Significant number of post-graduate Gynae trainees have varying degree of depression, anxiety, and stress ranging from mild, moderate, severe and very severe according to DASS-21 scale

\section{REFERENCES}

1. Guo YR, Cao QD, Hong ZS, et al. The origin, transmission and clinical therapies on coronavirus disease 2019 (COVID19) outbreak - an update on the status. Mil Med Res. 2020;7(1):11. Published 2020 Mar 13. doi:10.1186/s40779020-00240-0.

2. World Health Organization. Coronavirus disease (COVID-19) outbreak. http://www.euro.who.int/en/healthtopics/healthemergencies/coronavirus-covid-19/novelcoronavirus-2019-ncov.

3. World Heath Organization. WHO announces COVID-19 outbreak a pandemic. 12-03-2020. http://www.euro.who.int/en/healthtopics/healthemergencies/coronavirus-covid-19/news/news/ 2020/3/whoannounces-covid-19-outbreak-a-pandemic.

4. Lai J, Ma S, Wang Y, et al. Factors Associated With Mental Health Outcomes Among Health Care Workers Exposed to Coronavirus Disease 2019. JAMA Netw Open. 2020;3(3):e203976. Published 2020 Mar 2. doi:10.1001/jamanetworkopen.2020.3976.

5. Kisely $S$, Warren N , McMahon L , et al. Occurrence, prevention, and management of the psychological effects of emerging virus outbreaks on healthcare workers: rapid review and meta-analysis. BMJ 2020;369:m1642.

6. Lai J, Ma S, Wang $Y$, et al. Factors associated with mental health outcomes among health care workers exposed to coronavirus disease 2019. JAMA Network Open 2020;3:e203976.

7. Huang Y, Zhao N . Generalized anxiety disorder, depressive symptoms and sleep quality during COVID-19 outbreak in China: a web-based cross-sectional survey. Psychiatry Res 2020;288:112954.

8. $\mathrm{Lu} \mathrm{W}$, Wang $\mathrm{H}$, Lin $\mathrm{Y}$, et al. Psychological status of medical workforce during the COVID-19 pandemic: a crosssectional study. Psychiatry Res 2020;288:112936.

9. Khanna RC ,Honavar SG , Metla AL , et al. Psychological impact of COVID-19 on ophthalmologists-in-training and practicing ophthalmologists in India. Indian $\mathrm{J}$ Ophthalmol 2020;68:994-8

10. Atif K, Khan HU, Zia-Ullah M, Shah FS, Latif A. Prevalence of anxiety and depression among doctors; the unscreened and undiagnosed clientele in Lahore, Pakistan. Pak J Med Sci. 2016; 32 (2):294-298.

11. Naeem A, Shaikh AA, Hassan SU, Abid H, Tahir A.Frequency of Workplace Burnout among Postgraduate Trainees in a Teaching Hospital in Mirpur. Cureus.2019; 11(2): e4016

12. Imran N, Masood HM, Ayub M, Gondal KM. Psychological impact $f$ COVID-19 pandemic on postgraduate trainees: a crosee-sectional survey. Postgrad Med J.2020. e138364.

13. Civantos AM, Byrnes $\mathrm{Y}$, Chang C, Prasad A, Chorath $\mathrm{K}$, PooniaSk, et al. Mental health among otolaryngology resident and attending physicians during the COVID-19 pandemic: National study. Head \& Neck.2020; 42 (7):26292

14. Sandesh R, Shahid W, Dev K, Mandhan N, Shankar P, Shaikh A. Impact of COVID-19 on the Mental Health of 
Healthcare Professionals in Pakistan. Cureus. 2020; 12(7) e8974.

15. Sultana R, Sohail N, Naz R. COVID-19 pandemic: Psychological impact on postgraduate gynae residents in Pakistan. Annals of PIMS-Shaheed Zulfiqar Ali Bhutto Medical University. 2020 Nov 23;16(3):113-7.

16. Tan BY, Chew NW, Lee GK, Jing M, Goh Y, Yeo LL, Zhang K, Chin HK, Ahmad A, Khan FA, Shanmugam GN. Psychological impact of the COVID-19 pandemic on health care workers in Singapore. Annals of internal medicine. 2020 Aug 18;173(4):317-20.

17. Elbay RY, Kurtulmuş A, Arpacıoğlu S, Karadere E. Depression, anxiety, stress levels of physicians and associated factors in Covid-19 pandemics. Psychiatry research. 2020 Aug 1;290:113130.

18. Lai J, Ma S, Wang Y, Cai Z, Hu J, Wei N, Wu J, Du H, Chen $\mathrm{T}$, Li R, Tan H. Factors associated with mental health outcomes among health care workers exposed to coronavirus disease 2019. JAMA network open. 2020 Mar 2;3(3):e203976-

19. Kannampllil TG, Goss CW, Evanof BA, Strickland JR, McAlister RP, Duncan J. Exposure to COVID-19 patients increases physician trainee stress and burnout. PLoS ONE. 2020.15(8):e0237301

20. Mazhar SB, Gilani S, Khan S. High burnout among doctors working in a tertiary care hospital; a wakeup call. JPMA JPak Med Assoc.2019; 69 (3):349-54

21. World Health Organization. Doing What Matters in Times of Stress: an illustrated guide. WHO 2020. Available at: https://www.who.int/publications-detailredirect/9789240003927

22. Galbraith N, Boyda D, McFeeters D, Hassan T. The mental health of doctors during the COVID-19 pandemic. BJPsych bulletin. $2021 \mathrm{Apr} ; 45(2): 93-7$.

23. Braquehais MD, Vargas-Caceres S, Gomez-Duran E, Nieva $\mathrm{S}$, Casas M, Bruguera $\mathrm{E}$. The impact of the COVID-19 pandemic on the mental health of healthcare professionals. QJM.2020;113 (9):613-17.

24. Duan L, Zhu G. Psychological interventions for the people affected by COVID-19 epidemic. The Lancet Psychiatary.2020; 7(4):300-2. 